\title{
Savings and Incomes of Households and Inclusive Growth
}

\author{
Prof. Dr. Ercan Uygur (Turkish Economic Association, Turkey)
}

\begin{abstract}
This paper has three aims. The first is to explore the savings behavior of different income groups of households, with an emphasis on those with low incomes. This is achieved by going through the Household Budget Surveys (HBS) in some developing and developed countries. The HBSs reveal that the majority of poor sections of the societies do not save or have negative savings. The second aim of the paper is to explain the economic and social aspects of the savings behaviour of income groups, particularly those with low incomes. The paper explains that the "no saving/dissaving" behaviour of the low income groups and the resultant factors create economic and social problems. In this context, the paper also dwells on wealth distribution and issues of inclusive growth. The third aim of this paper is to examine policies implemented to encourage savings in general and savings of the low income groups in particular. To this end, policies pursued in some developing and developed countries are evaluated with reference to inclusive growth.
\end{abstract}

The author has requested that the full text of the paper to be withheld from the proceedings. 